\title{
The Relationship between Sexual Harassment and Job Satisfaction in the Context of Retailing Industry in China
}

\author{
Choi Sang Long (Corresponding author) \\ Raffles University Iskandar \\ Malaysia \\ Email: cslong_1@yahoo.com \\ Zhao Lingyun \\ Universiti Teknologi Malaysia, Malaysia
}

Tan Owee Kowang

Universiti Teknologi Malaysia, Malaysia

Goh Chin Fei

Universiti Teknologi Malaysia, Malaysia

Wan Khairuzzaman Wan Ismail

Universiti Teknologi Malaysia, Malaysia

Received: September 27, 2016 Accepted: October 13, 2016 Published: December 01, 2016 doi:10.5296/ijhrs.v6i4.10077 URL: http://dx.doi.org/10.5296/ijhrs.v6i4.10077

\begin{abstract}
The purpose of this study is to investigate the relationship between sexual harassment and job satisfaction in one of the China's retailing company. A total of 103 respondents from one of the China's retailing company are selected as respondents and thus data is analyzed based on the completed questionnaires. Sexual Experiences Questionnaire (SEQ) and Job Satisfaction
\end{abstract}


Survey are employed as measurement tools to measure the sexual harassment and job satisfaction of employees separately. Descriptive analysis, correlations analysis and multiple regression analysis are utilized to analyze the collected data. The main findings revealed that sexual harassments, verbal conduct of sexual harassments and physical conduct of sexual harassments have a significant and negative relationship with job satisfaction and the non-verbal conduct of sexual harassment is not significantly related to the job satisfaction. The dominant element of sexual harassment is physical conduct of sexual harassment affecting on job satisfaction mostly among female employees in the organization. In addition, it is also found that the moderate level of sexual harassment creates a low level of job satisfaction in the organization. Furthermore, the dominant sexual harasser is often a colleague, followed by a superior, customer and others. Several recommendations are suggested for the company and for future researches.

Keywords: Sexual harassment, Verbal sexual harassment, Physical sexual harassment, Non-verbal sexual harassment, Job satisfaction.

\section{Introduction}

Sexual harassment as a social problem had existed in every phase of the society for a long-term. It can be tracked from the industrial period of the development of human society; masses of women participate in the work field instead of staying at home to do housework, which brings the problem of economic oppression and discrimination from men at the same time. One of the problems is that sexual harassment has become a significant social issue (Keith, 2012). Furthermore, researchers have found that sexual harassment experiences are negatively related with job-related outcomes, psychological health, and physical health conditions (Chan et al. 2008).

Parish, Das and Laumann (2006) suggests that as China's economy has undergone a massive transformation in the last two decades, so has its society, including its views of sex and of women. The rise of China's urbanization, Chinese women are increasingly found in places - schools, work and public transportations-where there are more opportunities for them to be exposed to sexual harassments. Women in service jobs and those perceived by men as being more attractive than others also faced higher rates of harassment incidents. Sexual harassment is soon to become a crime in China under new gender equality laws as the state media have quoted.

Targets of sexual harassment were most likely to work in the retail trade as said in a Human Rights and Equal Opportunity Commission report. The commission's report, based on a household telephone survey in 2003 on 1,006 Australians aged 18 to 64, showed that 16 per cent of those surveyed who experienced harassments had worked in the retail trade (Smith, 2004).

An industry classification system was used to code sexual harassment complaints at workplaces of Australians and New Zealand (Charlesworth, et al., 2009). The industry in which complainants alleged that they were harassed could be determined in 279 of the 284 
complaints $(98 \%)$. The retail trade industry had the largest number of complaints lodged (49, $18 \%$ ), followed by the accommodation and food services industry with 30 complaints (11\%). In contrast, female complainants were more likely to work in the retail trade industry $(18 \% \mathrm{v}$ $13 \%)$ and the accommodation and food services industry $(12 \% \mathrm{v} 7 \%)$. In the aggregate Commission data the retail industry had the largest proportion of formal complaints, a proportion that is over-represented when employees' distribution across the industry is taken into account (Charlesworth, et al., 2009).

Several other studies show that there are substantial differences in perceptions of sexual harassment in line with country of residence (Fiedler and Blanco 2006; Matsumoto and Juang 2013; Tudor 2010). For example, in some countries there are women who are likely to tolerate sexual harassment for various cultural reasons and men who are more likely to sexually harass others (Cortina and Wasti 2005; Luthar and Luthar 2007). Although it is often assumed by China female employees that sexual harassment affects work outcomes similarly in all cultures, this assumption has not been empirically tested. Consequently, this study considers whether the experience of sexual harassment impacts productive work environments for employees in China, how it affects job satisfaction.

\section{Previous Studies on the Relationship between Sexual Harassment and Job Satisfaction}

One national study, commissioned by the Ministry of Women, Family, Youth, and Health, surveyed the incidence responses to and consequences of sexual harassment in Germany; and was conducted by Sozialforschungsstelle Dortmund (Holzbecher, Braszeit, Müller and Plogstedt, 1991). The methods used included qualitative interviews and large-scale quantitative surveys, data taken from 1981 women employees. The most frequently experienced verbal conduct of sexual harassments were jokes with sexual innuendoes $(81 \%)$ and unwanted invitations with definite sexual intentions (35\%); The most frequently experienced physical conduct of sexual harassment were "accidental" touches (70\%) and pinching or patting on the behind (35\%); And the most frequently experienced non-verbal conduct of sexual harassments was staring, whistling (84\%) and pornographic pictures $(35 \%)$. As a consequence of the harassment for one in five female respondents the experience of sexual harassment leads to less work-related satisfaction.

In 1993 a survey send to all employees (2558 women and 2559 men) of Gothenburg University in Swedish, results show most often reported the verbal conduct of sexual harassment: unwelcome jokes (39\%); unwelcome sexual comments regarding appearance, clothing and private life (36\%); and pressure for sexual favors or a sexual relationship (8\%); the physical conduct of sexual harassment was unwelcome sexual touching such as pinching, rubbing, brushing against (62\%); and the non-verbal conduct of sexual harassment: unwelcome sexual innuendoes, looks and gestures (48\%); and unwelcome telephone calls, letters, pictures, and objects of a sexual nature (6\%). The report stresses the negative consequences of sexual harassment for the university employees, lessened the job satisfaction (Andriansson, 1993). 
The Congress asked the U.S. Merit Systems Protection Board (U.S. MSPB, 1994) to determine the nature and extent of sexual harassment in the Government workplace. $44 \%$ of women responding to the survey reported that they had experienced some form of unwanted sexual attention during the preceding 2 years. Survey respondents were asked whether they would classify as sexual harassment six kinds of behavior, ranging from sexual comments to pressure for sexual favors. The survey results show that the less severe forms of sexually harassing behaviors are the most prevalent while the most severe behaviors occurred the least often. The female respondents said they had experienced unwanted verbal conduct of sexual harassment behaviors: Teasing, jokes, remarks, or questions (37\%); pressure for dates (13\%); and pressure for sexual favors (7\%); The unwanted physical conduct of sexual harassment behaviors: Deliberate touching, leaning, cornering (24\%); and stalking (7\%); The unwanted verbal conduct of sexual harassment behaviors: Sexual looks, gestures (29\%); and letters, calls, sexual materials (10\%). The study noticed that the impact of unwanted sexual behaviors on job satisfaction in the workplace like filing grievances or discrimination complaints.

The women's section of the city of Graz in Austria commissioned a study on the job satisfaction of female and discrimination against female employees in public administration, university, and private sector. The Graz survey found that 362 (73\%) female respondents had been confronted with harassments by men or had witnessed men harassing another female. Remarks about bodies against the women's will were the most often reported verbal conduct of harassment (64\%). Almost 50\% of the women remembered observing women being put down verbally by men and $43 \%$ remembered men using pet names for women. There were $11 \%$ of the women who had been offered sexual relationship by a man with the promise of professional advantage. Physical sexual harassment including touching was reported by $37 \%$ of the women. $10 \%$ of the women had been directly asked to have sexual contact. $5 \%$ of the women knew about women being physically threatened by men. The non-verbal conduct of sexual harassment: while staring and being observed in a critical, examining way was experienced by $57 \%$ of the women, $46 \%$ of the respondents had noticed being whistled at. About $46 \%$ of the women noticed men not keeping the appropriate distance from women. The study found a connection between job satisfaction and the observation or experience of harassing behavior. Those women who reported more harassment showed more work-related dissatisfaction while the women who were more satisfied tended to report less harassment (Kapeller and Scambor, 1994).

Roethleitner (1995) studied the relationship between work-related dissatisfaction among female employees and sexual harassment in the workplace. The convenience sample was composed of $1 / 3$ nurses, $1 / 3$ saleswomen, and 1/3 secretaries. The main finding was that the female secretaries and nurses experienced more verbal sexual harassments and interpreted more situations as harassing than saleswomen. Also the main findings were that females working in shops were more often harassed and more likely to be harassed physically; only 26\% were satisfied with their jobs. Female respondents who had not reported sexual harassment were more satisfied with their work and felt less indifferent towards their work than those who had experienced sexual harassment. 
According to Siddiqi (2003), a study was discussed on the sexual harassment of industrial workers on March 4, 2003 at CIRDAP Auditorium, Dhaka. The questionnaire based opened-ended interviews without specific limitations on time whereby the informal conversations and group discussions methods were taken from 81 female industrial workers. In answer to the question of whether they had ever been sexually harassed, $24 \%$ of women replied in the positive. Female workers in the Bangla factories also accused supervisors, linemen, line chiefs, and production managers indulge in verbal jousting or baiting, invited the women to go out. When asked if they had ever been physically harassed (that is, subjected to any unwanted physical contact), $22 \%$ of the women reported having had such experiences. Workers in the Bangla factories also accused supervisors, linemen, line chiefs, and production managers of various forms of physical sexual harassment: stroking, touching the body, and even kissing workers as the latter sit at their machines. Also the workers in the Bangla factories also accused supervisors, linemen, line chiefs, and production managers may stand too close, and have been encountered non-verbal forms of sexual harassment include winking, staring, whistling, standing very close and pinching. The finding found that the female workers who had encountered the sexual behavior easily get unsatisfied with the job in the Bangla factories.

A previous study explored the extent to which female sport print media professionals were subjected to sexually harassing behaviors in the workplace. 57 (50.9\%) of the 112 participants had encountered some form of sexual harassment over the previous year from others in the workplace. The 57 females who encountered sexual harassment reported they faced multiple forms of sexual harassment: 52 incidents of verbal conduct of a sexual nature, 27 incidents of unwelcome sexual advances. Some of the 57 females who encountered sexual harassment reported they faced physical form of sexual harassment: 27 incidents of unwelcome sexual advances and 14 incidents of physical conduct of a sexual nature. Data analysis of the satisfaction on the female sport media professionals had with the resolution of reported incidents of sexual harassment indicated that those who were less satisfied with negative consequences will impact job satisfaction (Pedersen, Osborne, Whisenant and Choong, 2009).

The study was aimed to investigate what female employees in the three international banks situated in Harare's CBD (Barclays, Standard Chattered and Stanbic banks) view as the causes and consequences of sexual harassment in Zimbabwe. An interview schedule was administered personally to 63 female respondents approximately in 45 minutes to an hour. Participants' experiences of the sexual harassment include: being told a suggestive story $(37 \%)$; asked for dates $(30 \%)$; and victims of offensive jokes (10\%), the average percentage of women who had experienced verbal forms of sexual harassment was about a third. The female respondents who had experienced physical forms of sexual harassment include: physically touched (33 or 52\%) and an attempt had been made to stroke or fondle (14\%). The female respondents who had experienced the low incidence of sexist or suggestive materials (19\%), e.g. pictures, stories or pornography; and been treated different because of their sex. According to Glomb, Munson, Hulin, Bergman and Dragsgow's (1999) Structural Equation Model, results indicated that a negative job-related outcome of sexual harassment influences 
a decrease in the job satisfaction (Kariaga, 2010).

According to Fayankinnu (2012), a research examines the female executives' experiences of 'contra-power sexual harassment'. The questionnaire schedules are the instruments utilized for collection of qualitative and quantitative data from 115 respondents in Nigerian organizations. The percentage of distribution showing female executives' experiences verbal conduct sexual harassments include: bragging the sexual prowess $(58.2 \%)$, bragging the size of sexual organs (59.7\%), sexually patronizing comments about female executives (41.8\%) and verbal discussions with sexual undertones (35.8\%). The percentage distribution showing female executives' experiences of physical conduct sexual harassment include: Prolonged handshakes (34.4\%), unwanted touch on body (25.4\%) and frontal hugging with suggestive meanings $(16.4 \%)$. The percentage distribution showing female executives' experiences of physical conduct sexual harassment include: grabbing groins (61.2\%), suggestive gifts (37.4\%), lustful look at you (35.8\%) and suggestive text-messages (16.4\%). The findings from a significant number of the participants point to the fact that the verbal conduct of sexual harassments impact negatively on job satisfaction.

\section{Three Elements of Sexual Harassment}

Three elements of Sexual Harassment are to be examined in this study. These elements are verbal conduct of sexual harassment, physical conduct of sexual harassment and non-verbal conduct of sexual harassment.

\subsection{Verbal Conduct of Sexual Harassment}

Verbal conducts of sexual harassment include comments on your clothes, personal behavior or opinions of your body; sexual or gender-based jokes; asking you out or asking sex favors; sexual innuendo; or dissipating rumors on your personal life; or threatening a person (Kariaga, 2010). To explain the organizational culture of sexual harassment in the workplace a questionnaire had been widely used (U.S. MSPB, 1994). In this questionnaire, participants were invited to use the 5-point scale from 1 (never) to 5 (usually) to indicate the frequencies in the past 12 months on experiencing unwanted sexual behavior. At this point, 6 verbal forms are included: remarks about someone's sex life; of obscene remarks about personal appearance; sexual jokes / general offensive words; words of indecency about the clothes; invite ulterior motives; and others put under pressure to the threat of violence, extortion (Timmerman \& Bajema, 2000).

U.S. MSPB (2007) listed some examples of verbal conduct of sexual harassment: Sexual jokes or suggestive verbal communication; unwelcome telephone calls of a sexual nature; degrading or demeaning remarks of a sexual nature; using threats of punishment to attempt to force sexual activity or other sexual conduct; sexual propositions that either overtly or by implication, promise rewards; calling out to someone in a sexual way.

\subsection{Physical Conduct of Sexual Harassment}

Physical conducts of sexual harassment include rape or assault; impeding or preventing your movement; inappropriately touching your body parts or clothing; kissing, hugging, patting, or 
even stroking. Some researchers have found that rapists can be characterized by traditional gender role attitudes (Koss, Leonard, Beezly, \& Oros, 1985). Scholars also suggest that sexist attitudes and sexual harassment (Elizabeth \& Solomon, 1989) are similar to the relationship between them. Some harassment issues have become a "likelihood of sexual harassment" (LSH) concept knowledge, developed by Pryor and his colleagues (Pryor, LaVite, \& Stoller, 1993).

Studies have shown the recent trends of sexual harassment namely individuals tend to sexually harass only if circumstances permit them to do so. As the man who wants to sexually harass his female employees, he will definitely have more of such opportunities. Organizing an environmental permit or facilitating such behavior will be a boost. Generally speaking, there is a growing trend that organizational characteristics play a role in determining the incidence of sexual harassment (Stockdale, 1996).

Timmerman and Bajema (2000) have explained the impacts of organizational culture on the incidence of unwanted sexual behavior in the workplace. At this point, 4 physical forms of sexual harassment are listed, which include touching (for example hugging and kissing); access to specific parts of the body; (attempted) attack; and (attempted) rape.

\subsection{Non-verbal Conduct of Sexual Harassment}

Non-verbal conducts of sexual harassment include looking up and down the body; derogatory gestures or facial expressions of a sexual nature; following or tracking you; posters, drawings, photos, screensavers or sex-related e-mail. Organizations do not need to explain the factors affecting sexual behavior in the workplace on the basis of a questionnaire widely used (U.S. MSPB, 1994). Candidates were invited to represent the five-point scale, from 1 (never) to 5 (usually) on how often they had experienced sexual harassment in the form of non-verbal. They include: sexually offensive texts/pictures on the computer; nude scenes or acts; display / hang up porn, foot-ups, nude calendars; and obtrusiveness (hanging over a person, blocking the road, the next). Respondents were asked to fill in for this unwanted behavior they have observed in their own departments (Timmerman \& Bajema, 2000).

U.S. MSPB (2007) listed some examples of nonverbal conduct of sexual harassment: Distribution or display of materials of a sexual nature, this includes but is not limited to posters, calendars, screen savers or similar items; suggestive body language such as ogling, staring, leering, lewd licking of lips, or suggestive touching of oneself; unwelcome letters, notes or e-mails of a sexual nature.

Extend the definition of workplace sexual harassment beyond the physical office space and beyond staff directly employed by the company - protection should be provided for any work-related incident of sexual harassment, no matter the time or place it occurs and whether the harasser is a co-worker, client, customer or vendor". Workplace policy must take into account all persons who interact with the particular workplace. This interaction must consider non-physical forms such as telephonic conversations, internet and email communication among others (Kariaga, 2010). 


\section{Macrothink}

\section{Purpose of Study}

The purpose of this study is to examine the impact of sexualharassment on job satisfaction. Base on the above literature review on various previous studies, Three elements of sexual harassment identified that link closely with job satisfaction are verbal conduct of sexual harassment, physical conduct of sexual harassment and non-verbal conduct of sexual harassment. Therefore a conceptual framework is developed as illustrate in Figure 1.

\section{Variable}

\section{Dependent Variable}

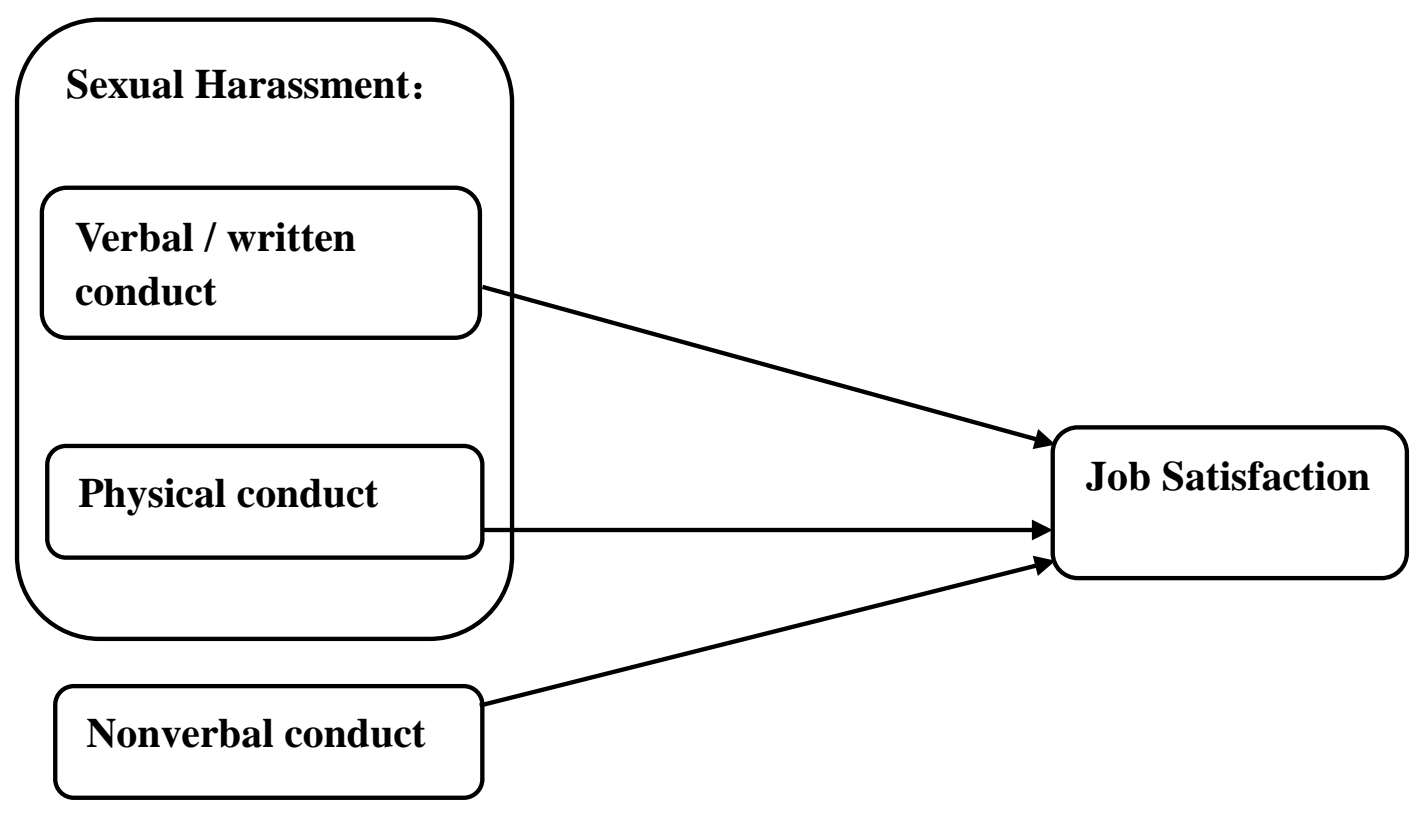

Figure 1: Conceptual framework

\section{Research Method}

In this study, a questionnaire as the quantitative research is employed to collect data in selected sample from the target populations. The questionnaire is used by the researcher for the purpose of the research. The collected data will be analyzed through statistically using the SPSS software package. Inferential statistical analysis will be conducted in order to achieve the objectives of this study. The Likert scale rating is used for data collection.

A pilot study was done to examine the reliability of the instrument used. In order to ensure the reliability of the instruments, the internal consistency method was employed using reliability coefficient, which known as Cronbach's alpha. The items were considered to represent an acceptable level of internal consistency if the Cronbach's alpha value within 0.5 
to 0.9 , and good level if the Cronbach's alpha value more than 0.7 and less than 0.9 (George $\&$ Mallery, 2003). Based on Table 1, most of the variables with the Cronbach's alpha values more than 0.7 at good level. The term non-verbal conduct of sexual harassment with Cronbach's alpha value 0.529 is at lower level but still can be accepted. This implied all items from the variables are statistically reliable.

Table 1: Reliability Analysis (Cronbach’s Alpha)

Variable Cronbach's Alpha $\quad$ N of Items

$\begin{array}{lcc}\text { Verbal Conduct of Sexual Harassment } & 0.773 & 6 \\ \text { Physical Conduct of Sexual Harassment } & 0.708 & 3 \\ \text { Non-verbal Conduct of Sexual Harassment } & 0.529 & 3 \\ \text { Overall Sexual Harassment } & 0.839 & 12 \\ \text { Job Satisfaction } & 0.736 & 6\end{array}$

Below are some items in the instrument used to measure the independent variable (Conduct of Sexual Harassment):-

While at the work place, have you ever been in a situation where any individuals...

1. told dirty or sexually offensive jokes?- Verbal conduct

2. commented on your physical appearance( clothing, body or personal behavior) that offended or embarrassed you?-Verbal Conduct

3. have continued to ask you out (date, drinks, dinner, etc.,) even though you have said "no"? - Verbal Conduct

4. made unwanted attempts to (stroke/patted/kissed/hugged) you? -Physical Conduct

5. displayed, used, or distributed sexist or suggestive materials (e.g., Posters, drawings, pictures, screensavers or e-mails of a sexual nature.)? -Non Verbal Conduct.

A retailing company in Henan province in China, Zheng Zhou city is chosen for this case study. The name of the organization is not disclosed as requested by the company management team. Therefore, in this paper, the organization will be named as "ABC Company". ABC company was originally founded in USA. Over the past 50 years, the company has served customers and is now the world's largest private employer and retailer. $\mathrm{ABC}$ was ranked on the top of the Fortune 500 list several times and is among the most 
recognized global brands. In China, ABC has been operating 433 retail units covering 169 cities among 19 provinces, 2 autonomous regions and 4 municipalities nationwide; as well as running 9 distribution centers and 11 fresh products distribution centers. From 2015- 2017, $\mathrm{ABC}$ will increase investment across diverse business operations in China by opening up to 115 new facilities creating more than 30,000 job opportunities.

The respondents are the female employees from two branches of ABC Company. They are considered to be the appropriate subject for this research because they have sexual harassment experience in the workplace that would help this study seeking better perception of the services provided by ABC Company. There are 103 usable survey forms returned by respondents out of total 110 survey forms that are distributed.

\section{Findings}

Research objectives are tested by using mean score, frequency analysis, Pearson's correlation analysis and multiple regression analysis as shown below:

Table 2: Sexual Harassment and Job satisfaction Level

$\begin{array}{lrl}\text { Sexual harassment } & 3.24 & \text { Moderate Level } \\ \text { Job Satisfaction } & 2.24 & \text { Low Level }\end{array}$

Table 2 shows the mean value of sexual harassment is 3.24 , and job satisfaction is 2.24 . Therefore, the sexual harassment is at moderate level, and the respondents' job satisfaction is at the low level in the ABC Company.

Table 3: Pearson's Correlation between Variables

\begin{tabular}{llllll}
\multicolumn{2}{l}{ Pearson's Correlation } & & & \\
\hline $\mathrm{N}=100$ & $\mathrm{VCSH}$ & $\mathrm{PCSH}$ & $\mathrm{NCSH}$ & $\mathrm{SH}$ & $\mathrm{JB}$ \\
\hline $\mathrm{VCSH}$ & 1 & $0.799^{* *}$ & $0.299^{* *}$ & $0.940^{* *}$ & $-0.664^{* *}$ \\
$\mathrm{PCSH}$ & $0.799 * *$ & 1 & $0.293^{* *}$ & $0.886^{* *}$ & $-0.712^{* *}$ \\
$\mathrm{NCSH}$ & $0.299 * *$ & $0.293^{* *}$ & 1 & $0.546^{* *}$ & -0.041 \\
$\mathrm{SH}$ & $0.940^{* *}$ & $0.886^{* *}$ & $0.546^{* *}$ & 1 & $-0.642^{* *}$ \\
$\mathrm{JB}$ & $-0.664 * *$ & $-0.712^{* * *}$ & -0.041 & $-0.642^{* * *}$ & 1 \\
\hline
\end{tabular}


** Correlation is significant at the 0.01 level (2-tailed).

VCSH = Verbal conduct of sexual harassment; PCSH = Physical conduct of sexual harassment; $\mathrm{NCSH}=$ Non-verbal conduct of sexual harassment; $\mathrm{SH}=$ Sexual harassment; JB = Job Satisfaction.

Table 3 shows that the relationship among three element of sexual harassment, sexual harassment (positive relationship) and job satisfaction (negative relationship). The verbal conduct of sexual harassment have strongest correlation with sexual harassment $(r=0.940, p$ $<0.01)$; and next is physical conduct of sexual harassment $(\mathrm{r}=0.886, \mathrm{p}<0.01)$; then the non-verbal conduct of sexual harassment have a less correlation with sexual harassment $(\mathrm{r}=$ $0.546, \mathrm{p}<0.01)$. The value of the correlations between verbal conduct of sexual harassment and job satisfaction is negative and significant $(\mathrm{r}=-0.664, \mathrm{p}<0.01)$; the value of the correlations between physical conduct of sexual harassment and job satisfaction is negative and significant $(\mathrm{r}=-0.712, \mathrm{p}<0.01)$; and the value of the correlations between non-verbal conduct of sexual harassment and job satisfaction is not significant $(r=-0.041, p=0.682>$ $0.05)$.

Table 4. Multiple regression analysis for sexual harassment on job satisfaction

\begin{tabular}{lllllll}
\hline Model & $\mathrm{R}$ & $\mathrm{R}^{2}$ & Adjusted $\mathrm{R}^{2}$ & $\begin{array}{l}\text { Std. Error of } \\
\text { the Estimate }\end{array}$ & $\mathrm{F}$ & Sig. F \\
\hline 1 & $0.755^{\mathrm{a}}$ & 0.569 & 0.556 & 0.25614 & 42.323 & 0.000 \\
\hline
\end{tabular}

Sexual Harassment Elements

$\begin{array}{ll}\text { Beta } & \text { Sig. } \\ & \text { VIF }\end{array}$

Verbal conduct of sexual harassment

$-0.301$

0.009

Verbal conduct of sexual harassment

(0.301

2.800

Physical conduct of sexual harassment

$-0.532$

0.000

2.789

Non-verbal conduct of sexual harassment

0.204

0.005

1.108

Base on the Table 4, it is found that sexual harassment elements overall has negative relationship with job satisfaction $(\mathrm{R}=0.755)$. However, based on the adjusted $\mathrm{R}$ square value of 0.0 .556 , these elements only contribute $55.6 \%$ to dependent variable (job satisfaction). 


\section{Macrothink}

The verbal conduct and physical conduct of sexual harassment give significant impact to job satisfaction. It is clear that in dependent variable with higher level of $\beta$ has higher impact on dependent variable. In this study result reveal that the factor of physical conduct of sexual harassment $(\beta=-0.532$, sig< 0.001$)$ is most influential factor and verbal conduct of sexual harassment with job satisfaction $(\beta=-0.301$, sig $<0.01)$ is ranked second. The non-verbal conduct of sexual harassment did not show any significant contribution. The non-verbal conduct of sexual harassment is as a suppression effect in multiple regression analysis, based on the Reciprocal Suppression model (Chen \& Krauss, 2004).

Furthermore, Table 4 indicates the value of the variance inflation factor (VIF). VIF quantifies the severity of multicollinearity in an ordinary least squares regression analysis. Since all VIF value in table 5 are below 5 , thus indicate multicollinearity problem does not exist in this study (George \& Mallery, 2003).

\section{Discussion}

The law rules and those breaking the law are more likely to be formally prosecuted in the U.S. workplace; and there are more likely to affect changes with regards to sexual harassments because the authority structure in the United States is based to a large extent on legitimate power (Raven and French 1958). These findings are consistent with those of Blando (2010), who stated that workplace sexual harassment has negative work related and personality related outcomes. These effects included feelings of helplessness and isolations, withdrawals, fear of being labeled as a troublemaker, fear of dismissal or loss of job promotion opportunities, fear of being transferred to dead-end or mundane jobs, low morale, low self-esteem, poor job performance, absenteeism, physical violence to others, and other additional impacts on the victims' life. These findings are consistent with the findings of Valente \& Bullough (2004) and Madison \& Minichiello (2001) that sexual harassment at a work place is linked with a weakening of interpersonal relationships, poor organizational commitment, lack of job motivation and low job satisfaction and higher levels of job stress, absenteeism and turnover.

Estrada et al (2011) found that perceptions of the psychological climate for sexual harassment (i.e., intolerance for sexual harassment) were associated with increased job satisfaction and organizational commitment as well as with better mental health and decreased psychological distress. These findings are consistent with extant theory and research on psychological climate for sexual harassment, which posit that working in an environment that is perceived to be tolerant of sexually harassing behaviors can have a negative impact on an employee's job and psychological outcomes (Chan et al., 2008). The impact that Sexual harassment experiences have on the victim is significant, including many job-related consequences such as decreased job satisfaction and organizational commitment and increased withdrawal behaviors. Sexual harassments also negatively affects the mental, physical, and psychological health of the victims, as evidenced in their higher rates of symptoms such as anxiety, depression and even the post-traumatic stress disorder (Willness, Steel \& Lee, 2007). 
Similar results are seen in Fister-Gale (2003), Kronos Incorporated (2005), and Merkin (2008) which reported that each year there is approximately 2.8 million lost work days due to job dissatisfaction and stress which includes the overall absenteeism, especially higher for employees experiencing sexual harassments than for employees not experiencing sexual harassments. These findings on job dissatisfactions also implicate an increase in the employers' medical expenses due to an increase in stress-related diseases and illnesses and injury claims. In turn, job withdrawal produces its own set of the costs. Thus, it is mandatory for employers to take precaution on sexual harassments as it is a warning sign to threaten a stable workforce as well as a productive workplace.

There are cases when the organization did not have clear policies on complaint and disciplinary procedures about sexual harassment; or the policies and procedures exist but no action is taken by the management. If the management condones such behaviors or if victims ended up being blamed, the perpetrator is encouraged to continue the pattern of harassments which is affecting more and more female employees (Dhawan, 2014). This kind of situation will lead to job satisfaction on the decrease more.

The ignorance of women about what actions constitute sexually harassing behavior also played a role in sexual harassment at their workplaces. The respondents revealed that they were not aware of existing sexual harassment policies at workplace, or put in place by the Law. The respondents said they were either not aware of the company's policies on sexual harassment or that their companies did not have a policy. The respondents thus could not personally attribute causes of sexual harassment to shortfalls in their own company policies (Kariaga, 2010). Pedersen et al (2009) found incidents of sexual harassment being affected by attitudes toward sexual harassment. Those who responded with active attitudes towards sexual harassments were less likely to encounter incidents of sexual harassments. Organization are required to set up appropriate policies in place with a clear reporting mechanism for sexual harassment to create an environment or culture to help victims to challenge the sexual harassment the first time an incident occurs; followed by the EEOC Guidelines (2006) requiring employers to affirmatively establish, post and inform their employees of sexual harassment policies and grievance procedures in place.

Some responses perceived traditional culture as playing a major role in promoting or enabling sexual harassment at their workplace. Men used traditional beliefs and culture to justify sexually harassing behavior. Bennett et al, (2007) reports that there is mention of confusion and anger concerning the relationship between challenges to certain forms of sexual abuse and the meaning of "cultural" norms concerning heterosexual masculinities". According to their findings, "practices such as men touching women without their permission through bottom-patting, palm-scratching, shoulder-rubbing, are defended as men's perceived 'right' to pursue women aggressively with overt interest in sexual liaison, regardless of the women's expressed disinterest" (Bennett et al, 2007). All of this is pursued in the name of traditional culture.

Lack of respect for women usually begins at a young age in school and or at home, alleges Morewitz (2009). Three of the responses to this research indicated lack of respect to be a 
cause of sexual harassment. Women may have felt that men lacked respect for them for various subjective reasons. It may have been due to socio-economic conditions of either the men or the women involved. Dougherty (2007) discovered that the sexual harassers can be any person who is perceived as having power of an organization. Blackstone, Uggen \& Mclaughlin (2009) also provided the strongest evidence at the time supporting the theory that sexual harassment is less about sexual desire than about control and domination. This explanation for sexual harassment at work showed that when there is a vast difference in power that is held by men in organizations, women are more likely to be sexually harassed (Johnson, Stockdale \& Saal, 1991).

Sexual harassment in a work place is a sensitive topic. The verbal conduct of sexual harassment sometimes were not recognized by the harassers as it looks more like the suggestive / offensive jokes, comments, or invitations. When males grouped together, they are bound to behave differently as compared to individuals. Some degree of verbal conduct of sexual harassment is expected to happen within the group in public places such as when they see a pretty woman walked past them during lunch break (Prekel, 2001). An additional reason that was cited by the women as a cause of sexual harassment was the fear of job loss. Fear of job loss may also prevent the harassed women from reporting. This may be exacerbated by nothing being done about the harassment by the management after reporting it and /or experiencing difficulty in dealing with the pain caused by the harassment itself, especially if the perpetrator is not penalized. The victim may feel embarrassed and self-conscious about it at the workplace (Noah, 2008).

These previous studies mentioned that the non-verbal sexual harassment happened among female employees in workplace, but the non-verbal sexual harassment was treated as one factor (independent variable) influence on decrease of the job satisfaction, the previous authors did not do a research and discussed on the relationship between non-verbal sexual harassment and job satisfaction. Both of the results of Pearson's correlation and multiple regression in this study, there is no evidence to prove the hypothesis that non-verbal sexual harassments have a significant negative relationship with job satisfaction.

Some reasons can be guessed for why the non-verbal conducts of sexual harassment were ignored: With the opening sexual conception been spread and accepted by the society; also there are some sexual information appeared in the advertisements and movies; even some feminist and sex educators are already asking for the rights of the people to have a correct perception on sex opinion. Usually when the non-verbal sexual harassment happened, it is easily being ignored and less impact on the victims. For example: the female respondents will warn the sexual harasser to stop the staring behaviors or gestures and ignore the sexual antics.

\section{Implications for Practice}

First, the ABC company should diagnose the extent and seriousness of sexual harassment this study and survey results so that they know what kinds of solutions are appropriate and where resources should be concentrated. Then the ABC should establish and publicize policies, emphasize a preventive policy on sexual harassment, failing which one will be held responsible and punished. Also a grievance procedure been built to deal with the sexual 
harassment reports in time, There are four main stages: i). Informal advice, an employee seeking information on an sexual harassment issue should obtain advice from an equity contact, manager, local human resources coordinator or consultant. ii). Informal conciliation, the complainant will be advised that the purpose of conciliation is to resolve the grievance. iii). Formal conciliation, the complainant is required to detail the nature of the grievance in writing. iv). Formal determination, the formal determination will make available all details of the grievance, the respondent's reply, investigation findings and actions undertaken in attempting conciliation. Usually, the sanctions include: unofficial warning on verbal, an official warning letter, offender been discipline like transfer or imposed, dismissal of the offender. The organization should publicize penalties and encourage assertive actions; to increase the public attention to sexual harassment has made employees more careful to avoid sexual harassment behavior. The sexual harassment training should be providing for all the employees, managers and supervisors, it also should focus on both the individual level and organizational level. Furthermore, the organization should protect victims from reprisal, like anonymous sexual harassment hotlines, anonymous letter box. Another way is introduce a confidential counselor, who can have the authority to investigate complaints and who can help achieve a solution. They could be chosen from the workers' elected representatives. These advisors would be people to whom complainants could go without fear of reprisal and with assurances, when the harasser is a manager or supervisor.

\section{Implication for Research}

This study should be continued and extended as deeper insights regarding the importance effecting of sexual harassment in the organization are needed; some recommendations also can be given to improve the research, like the most effective ways to deal with the

sexual harassment; investigate the real reasons of why sexual harassment happened, is that the lack of a legal framework or the lack of a correct sexual harassment recognition for public. So for the future research, it can be continued and extended with the different organization in different industries, to compare the sexual harassment average level, it also can be focus on sexual harassment negative effect on other job outcomes like: absenteeism, turnover, job stress and physical health.

\section{Conclusion}

This study explores the effect of three conducts (Verbal, physical and non-verbal conduct) sexual harassment and itself on job satisfaction in ABC Company in China. Based on previous studies, usually sexual harassment was researched as an independent variable with a negative effect on the work outcomes (especially the job satisfaction). In this study, the data is collected and analyzed from 103 female respondents. The findings support that there are significant negative relationships between the sexual harassments and job satisfaction in the organization. Particularly both the effects for verbal conduct and physical conduct of sexual harassment are significantly negative job satisfactions however; non-verbal conduct of sexual harassment has no significant effect to job satisfaction. Also this study found that the dominant element of sexual harassment is physical conduct of sexual harassment affecting on job satisfaction among female employees in the organization most. The main type of sexual 
harasser is colleague, followed by superior, customer and others. Thereby, this study provides evident explanations supporting that verbal and physical conducts of sexual harassment and itself have significant relationships with job satisfaction and verbal and physical conducts of sexual harassment and itself have a significant effect on job satisfaction.

\section{References}

Andriansson, L. (1993). Ett högt pris, kartläggning av sexuella trakasserier vid Göthenborgs universitet.

Bennett, J., Gouws, A., Kritzinger, A., Hames, M. and Tidimane, C. (2007). Gender is Over: Researching the Implementation of Sexual Harassment Policies in Southern African Higher Education. Feminist Africa 8, 83-104.

Blando, J. F. (2010). Workplace bullying: Aggressive behavior and its effect on job satisfaction and productivity. USA: LAP LAMBERT Academic Publishing.

Chan, D. K. S., Lam, C. B., Chow, S. Y. \& Cheung, S. F. (2008). Examining the Job-related, Psychological and Physical Outcomes of Workplace Sexual Harassment: A Meta-analytic Review. Psychological of Women Quarterly, 32, 362-376

Charlesworth, S., McDonald, P., Worley, A., Graham, T. \& Lykhina, A. (2009). Formal Complaints of Workplace Sexual Harassment Lodged with Australian Human Rights and Equal Opportunity Commissions. Sexual Harassment in Australia: Context, outcomes and prevention. From Queensland University of Technology and the University of South Australia.

Chen, P. \& Krauss, A. (2004). Suppression effect. In M. Lewis-Beck, A. Bryman, \& T. Liao (Eds.), Encyclopedia of social science research methods, 1102-1103. Thousand Oaks, CA: SAGE Publications, Inc. doi: http://dx.doi.org/10.4135/9781412950589.n989

Cortina L.M, \& Wasti S, (2005). Profiles in coping: responses to sexual harassment across persons, organizations, and cultures. Journal of Appled Psychology, 90(1),182-192.

Dhawan, V. (2014). Preventing Sexual Harassment at Workplace. International Journal of Computing and Corporate Research, 4.

Dougherty, D. S. (2007). Power and Sexual Harassment: Men and Women see Things Differently. Retrieved 6th April 2009 from Science Daily.

E. E. O. C. (2006). Guidelines on Discrimination Because of Sex, 29 C. F. R. 1604.11.

Estrada, A. X. \& Olson, K. J. (2011). Evaluating a Brief Scale Measuring Psychological Climate for Sexual Harassment. Military Psychol, 23(4), 410-432.

Fayankinnu, E. A. (2012). Female Executives' Experiences of Contra-power Sexual Harassment from Male Subordinates in the Workplace. Bangladesh e-Journal of Sociology, 9, 2. 


\section{MInstitute Macrothink $_{\text {Int }}$}

International Journal of Human Resource Studies

ISSN 2162-3058 2016, Vol. 6, No. 4

Fiedler A.M, Blanco I.R. (2006). The challenge of varying perceptions of sexual harassment: an international study. Journal of Behavioral Applied Management , 7, 274-292.

Fister - Gale, S. (2003). Sickened by the Cot of Absenteeism, Companies Look for Solutions: Internally Devised Cost-tracking Systems, Off-the-shelf Software and Outsourced Absence-reporting Services are all Growing in Popularity as Employers Try to Figure Out Where an Estimated 15 Percents of the Payroll is Going. Retrieved Oct. 2012, form http:www.biomedsearch.com.

George, D. \& Mallery, P. (2003). SPSS for Windows step by step: A simple guide and reference. 4th ed. Boston: Allyn \& Bacon.

Holzbecher, M., Braszeit, A., Müller, U. and Plogstedt, S. (1991). Sexuelle Belästigung am Arbeitsplatz. No. 260 in the series of the Bundesministeriums für Jugend, Frauen und Gesundheid, Stuttgart.

Johnson, C. B., Stockdale, M. S. \& Saal, F. E., (1991). Persistence of Men's Misperceptions of Friendly Cues across a Variety of Interpersonal Encounters. Journal of Interpersonal Violence, 18, 1222-1239.

Kapeller, M. D. and Scambor, E. (1994). Die Zufriedenheit von Frauen am Arbeitsplatz im Raum, Frauenreferat der Stadt Graz, Graz.

Kariaga, P. (2010). Women's Views on the Causes and Consequences of Sexual Harassment. Retrieved on Nov 15th, 2010, from University of the Witwatersrand.

Keith, D. (2012). Sexual Harassment: An Introduction to the Conceptual and Ethical Issues. Broadview Press. ISBN 978-1554810109

Koss, M. P., Leonard, K. E., Beezley, D. A. \& Oros, C. J. (1985). Non-stranger Sexual Aggression: A Discriminant Analysis of the Psychological Characteristics of Undetected Offenders. Sex Roles, 12, 981-992.

Kronos incorporated. (2005). The Case for a Total Absence Management Solution. Retrieved 26 Oktober 2012, from http://hr.knowledgestrom.com/kshr/sear ch/viewabstract/79254/index.jsp.

Luthar H.K \& Luthar V.K, (2007), A theoretical framework explaining cross-cultural sexual harassment: integrating hofstede and schwartz. Journal of Labor Research, 28(1),169-188.

Madison, J. \& Minichiello, V. (2001). Sexual Harassment in Healthcare: Classification of Harassers and Rationalization of Sex-based Harassment Behavior. Journal of Nursing Administration, 31(11), 534-543.

Merkin, R. S. (2008). The Impact of Sexual Harassment on Turnover Intentions, Absenteeism, and Job Satisfaction: Findings from Argentina, Brazil and Chile. Journal of International Women s Studies, 10, 1-15.

Morewitz, S. J. (2003). Stalking and Violence: New Patterns of Trauma and Obsession. NY: Kluwer Academic/Plenum Publishers. 
Matsumoto D.R, \& Juang L.P,. (2013), Culture and psychology. Belmont, CA, Wadsworth.

Noah, Y. (2008). Perceived Experience of Sexual Harassment. International NGO Journal, 3 (15), 122-127.

Parish, W. L., Das, A. \& Laumann, E. O. (2006). Sexual Harassment of Women in Urban China. Archives of Sexual Behavior, 35, 441-425.

Pedersen, P. M., Osborne, B., Whisenant, W. \& Choong, H. L. (2009). An Examination of the Perceptions of Sexual Harassment by Sport Print Media Professionals. Journal of Sport Management, 23, p335.

Prekel, T. (2001). Sexual Harassment: Causes, Consequences and Cures. Retrieved August, 2001, from https://www.westerncape.gov.za/text/2004/4/sexual_harassment_Second_upload.pdf

Pryor, J. B., LaVite, C. M. \& Stoller, L. M. (1993). A Social Psychological Analysis of Sexual Harassment: The Person/Situation Interaction. Journal of Vocational Behavior, 42, 68-83.

Raven, B. H. \& French, J. R. (1958). Legitimate Power Coercive Power, and Observability in Social Influence. Sociometry, 21(2), 83-97.

Roethleitner, C. (1995). Untersuchung zur sexuellen Belästigung von Frauen am Arbeits-platz und ihre Auswirkungen, unter Berücksichtigung der Arbeitszufriedenheit. Diplom Arbeit, Salzburg Universität.

Siddiqi, D. M. (2003). The Sexual Harassment of Industrial Workers: Strategies for Intervention in the Workplace and Beyond. Centre for Policy Dialogue - United Nations Population, Dhaka. Fund Paper 26.

Smith. B. (2004). Retail Trade Worst for Harassment. Retrieved 31 March 2004, from: http://www.theage.com.au/articles/2004/03/30/1080544487646.html

Stockdale, M. S. (1996). Sexual Harassment in the Workplace: Perspectives, Frontiers, and Response Strategies. Women and Work: A Research and Policy Series, 5. London: Sage.

Timmerman, G. and Bajema, C. (2000). The Impact of Organizational Culture on Perceptions and Experiences of Sexual Harassment. Journal of Vocational Behavior, 57, 188-205.

Tudor T (2010). Global issues of sexual harassment in the workplace. Franklin Business Law Journal, 4, 51-57.

Uggen, C. and Shinohara, C. (2009). Sexual Harassment Comes of Age: A Comparative Analysis of the United States and Japan. The Sociological Quarterl, 50, 201-234.

U.S. Merit Systems Protection Board. (1994). Sexual Harassment in the Federal Workplace: Is it a Problem? Washington, DC: Office of Merit Systems Review and Studies/U.S. Govt. Printing Office.

U.S. Merit Systems Protection Board. (2007). Sexual Harassment Policy and Procedures. Retrieved 


\section{Macrothink}

International Journal of Human Resource Studies

ISSN 2162-3058 2016, Vol. 6, No. 4

http://www.mspb.gov/netsearch/viewdocs.aspx ?docnumber=250652\&version=250924\&appli cation $=$ ACROBAT

Valente, S. \& Bullough, V. (2004). Sexual Harassment of Nurses in the Workplace. Journal of Nursing Care Quality, 19(3), 234-241.

Wiliness, C. R., Steel, P. and Lee, K. (2007). A Meta-Analysis of the Antecedents and Consequences of Workplace Sexual. Personnel Psychology, 60 (11), 127-162.

\section{Copyright Disclaimer}

Copyright for this article is retained by the author(s), with first publication rights granted to the journal.

This is an open-access article distributed under the terms and conditions of the Creative Commons Attribution license (http://creativecommons.org/licenses/by/3.0/). 